

ISSN 2278 - 0211 (Online)

\section{Funding Self-Employed Businesses in Ghana: The Short and the Long Run Models}

Nelson Kofi Adarkwah
Lecturer, Department of Secretary ship and Management Studies,
Sunyani Technical University, Ghana
Dauda Abdulai
Lecturer, Department of Liberal and Languages Studies, Tamale Technical University, Ghana
Bempong Emmanuel Kofi,
Senior Lecturer, Department of Communication Studies, Sunyani Technical University, Ghana
Dr. John Poku
Director of International Affairs, Kumasi Technical University, Ghana

\begin{abstract}
:
Unemployment has been a problem for both developed and developing countries and efforts are made by governments to find solution to the problem. In Ghana for example, the following measures have been taken by previous governments to tackle the situation in their attempts to solve it. First, the workers brigade was set up by $\mathrm{Dr}$ Nkrumah in the 1960s to employ some of the teeming youth who were unemployed. The Youth Employment Scheme started by the Kuffour regime was continued by the Mill's and Mahama's administrations between 2009 and 2016 and currently the Nana Addoh's regime (2017) have tried to create employment opportunities for the unemployed in the Ghanaian society. All these governments advocate for private sector participation in the employment sector to help solve the unemployment situation in Ghana. Many of such businesses are found in the informal sector and throughout the decades, instead of the informal sector disappearing as the modern economy expands, the informal sector has actually grown in the rural and urban areas of Ghana. The size of Ghana's informal sector is placed at 80 per cent of the total labour force. The large-scale retrenchment of labour as overriding consequences of Structural Adjustment Programme in Ghana in the mid-1980s, coupled with the inability of the government to provide employment for the emerging labour force has created a large pool of unemployed persons who have naturally gravitated towards the informal sector. According to studies the size of the informal sector employment in the 1980s was twice that of the formal sector. By the 1990s, the informal sector employment had increased by five and half $\left(5^{1 / 2}\right)$ times than that of the formal sector. One of the teething problems which is a thorn in the fresh of the informal sector is funding which most researchers agree but how do the self-employed overcome this social canker? Both short and long run models for raising self-funding of businesses have been provided in this study to help the self-employed tackle their financial problems. It is hoped that if prospective self-employed owners/managers go by the tenets of the models the financial constraints of the self-employed could be reduced if not eradicated.
\end{abstract}

Keywords: Unemployment, informal sector, labour force, short run period, long run period

\section{Introduction and Literature Review}

Ghana's population has a youthful structure with the youth (defined officially as aged 15 - 24 years) constituting about one out of every four of the population. Over the past forty years, the number of the youth in the total population of Ghana has increased from 1.1 million in 1960 to 2.3 million in 1984, and to 3.5 million in 2000. The latter constitutes about 22.6 percent of the economically active population Farrell et al (2000). According to Amankwah, (2006) a number of factors account for the growing youth unemployment in Ghana. Historical evidence indicates that youth unemployment in Ghana is due to, on one hand, a more than a threefold increase in the youthful population over the last forty years, and on the hand, failure of the economy to generate sufficient employment outlets. The Ministry of Manpower, Youth and Employment has identified a number of factors contributing to these phenomena. According to the Ministry of Manpower, Youth and Employment the causes of youth unemployment in Ghana include the following; the introduction of the Junior Secondary School and Senior Secondary School system without adequate planning for integration into the trades/vocations and job 
placement; education and training have no link to the needs of the important sectors of the economy; the near collapse of Ghana's industrial base due to ineffective management of the divestiture process which resulted in the closure of many factories without a structural transformation of the economy to generate alternative jobs for people; the shrinking of public sector employment opportunities coupled with a relatively slow growth of the private sector; and the lack of a coherent national employment policy and comprehensive strategy to deal with the employment problem (Nyameky 2009).

According to GSS (2008) throughout the decades, instead of the informal sector disappearing as the modern economy expanded, the informal sector has actually grown in the rural and urban areas of Ghana. The size of Ghana's informal sector is placed at 80 per cent of the total labour force (Hormeku, 1998). The large-scale retrenchment of labor as overriding consequences of Structural Adjustment Programme in Ghana in the mid-1980s, coupled with the inability to provide employment for the emerging labour force by the government has created a large pool of unemployed persons who have naturally gravitated towards the informal sector. According to Nyameky (2009), the size of the informal sector employment in the 1980s was twice that of the formal sector. However, by the 1990s, informal sector employment had increased by five and half $\left(5 \frac{1}{2}\right)$ times that of the formal.

The origin of the informal sector in Ghana's economy can be traced back to the very beginnings of colonial capitalism in the then Gold Coast (Wolf, 2010). As Cook et al (2012) indicated even at such an early stage an essential feature of labour in the informal sector was its heterogeneous character that provided for varieties of peasant proprietors and agricultural laborers, distribution agents, buyers, transport owners and employees, porters, repairers, among others.

Researchers such as Abor, (2010) and Warr et al (2017) have expressed the concern that though sole proprietorship businesses are numerous funding is one of the challenges affecting owners of self-employed businesses. It is because of this funding problem that this study has developed two models for funding self-employed businesses which could mitigate the financial challenges the self-employed owner/ managers go through.

\subsection{Statement of the Problem}

It is said that no government is self-sufficient to the extent that it will be able to find jobs for its citizenry (Miller, 2008). With this in mind the private sector is relied upon to give a helping hand to the government. In a developing economy like Ghana most self-employed are found in the informal sector and many researchers like SME Tool Box, (2008); Nyameky, (2009) and Wolf, (2010) among others have identified funding of businesses as a major challenge to owners of the selfemployed as was supported by Warr et al (2017). Questions like 'would the self-employed perform creditably if they had enough funds?'; how can the self-employed raise capital to finance their businesses rather than to rely on the financial institutions like the banks who charge high interest rates and some even run away with the hard earned monies saved with them?' These questions among others make it imperative for a model which seeks to bring into existence ways of funding selfemployed businesses be developed to serve as a guide to prospective owners of self-employed businesses. This study therefore presents two models which aim at guiding prospective and existing self-employed owners to either raise funds in the short or long run periods for their businesses.

\subsection{Objectives of the Study}

The study relied on two objectives which are general and specific. Generally the study will add to the body of knowledge on research work in funding of self-employed businesses in Ghana. Specifically the study aimed at providing models that can guide the self-employed to be able to generate funds themselves for their businesses either in the short run period or the long run period.

\subsection{Assumptions Underlying the Study}

The following assumptions among others underlie the two models which have been provided by the researchers.

- That there should be members in a group who have agreed to contribute some specific amounts of money at an agreed time period without fail.

- That the group members would be loyal and truthful to the group in terms of making periodic contributions.

- That each member of the group will live until the end of the period set for themselves.

- That no member of the group will be permitted to prematurely terminate his/ her membership in the group.

\subsection{Significance of the Study}

This study will be beneficial not only to owner/managers of businesses set up by individuals and prospective selfemployed owners but also stakeholders in business administration. For example the study could provide information to authorities in business administration and owner/managers of businesses as to what could be done to nip the funding challenges of the self-employed businesses in an economy to the background. The study will also be beneficial to financial institutions that may be the custodians of monies saved with them by contributors. Finally, other researchers who will be interested to have further studies in this area of study could use results from the study as a starting point.

\subsection{Limitations of the Study}


The study relies on some assumptions which may not hold in all situations. The short-run period requires the prospective self-employed owner or an existing owner of a self-employed business is to make a contribution of either five hundred Ghana cedis or one thousand Ghana cedis. These monies could be used as initial capital by somebody else to start a self-employed business. Also the terms short run and long run periods are relative because what may be considered by a firm or an individual as a short/ long run could be the vice versa to the other firm or individual. Finally, the researchers do agree that their model is not an end to all models that could be designed to assist the self-employed business owners to generate funds for their businesses.

\subsection{Delimitations of the Study}

The study is delimited to ways of funding the self-employed businesses in Ghana so results from the study are meant for such businesses. Though the savings practices as advocated by the study are similar to other saving methods there are some assumptions which may be absent in the normal savings practices. However in spite of the delimitations identified results from the study could be applied to other businesses that have similar characteristics like the self-employed business.

\section{Short Run Self-Financing Model}

Researchers such as Quartey (2002), Abor (2006) and Warr et al (2017) among others have identified funding as one of the major challenges facing small and medium scale enterprises which include sole proprietors in Ghana. The current study has come up with two proposed self- help funding models which aim at finding solutions if not minimizing the hardships most owners of self-employed businesses like the sole proprietors go through in their attempt to finding solutions to their teething problem of funds facing their businesses in Ghana. The researchers believe that if the models are studied carefully by businessmen/ women and they abide by the tenets involved in the models and apply them accordingly positive results could be attained. Model 1 guides businesses owners and prospective business owners as to what to do to save money in the short run for their businesses without resorting to the banks and other financial institutions in which they (owner/managers of small and medium size enterprises) would be required to pay the principal amount and its cut throat high interest rates. The worrying aspect of savings with some financial institutions especially with micro-financial institutions is that some of these firms run away with the hard worn monies earned by deposited as happened in the Brong-Ahafo region of Ghana recently.

\begin{tabular}{|c|c|c|c|c|c|c|c|c|}
\hline \multicolumn{9}{|c|}{$\begin{array}{c}\text { Months contributors Amount Payable Results } \\
\text { of The G1 G2 Gh\& Gh\& Pos Neg }\end{array}$} \\
\hline Year & 25 & 20 & TG1 & TG2 & G1 & $\mathrm{G} 2$ & G1 & G2 \\
\hline JAN & 25 & 20 & 12,500 & 20,000 & 5 & 4 & 20 & 16 \\
\hline FEB & 25 & 20 & 12,500 & 20,000 & 5 & 4 & 15 & 12 \\
\hline MAR & 25 & 20 & 12,500 & 20,000 & 5 & 4 & 10 & 8 \\
\hline APR & 25 & 20 & 12,500 & 20,000 & 5 & 4 & 5 & 4 \\
\hline MAY & 25 & 20 & 12,500 & 20,000 & 5 & 4 & 0 & 0 \\
\hline JUN & 25 & 20 & 12,500 & 20,000 & 5 & 4 & 20 & 16 \\
\hline JUL & 25 & 20 & 12,500 & 20,000 & 5 & 4 & 16 & 12 \\
\hline AUG & 25 & 20 & 12,500 & 20,000 & 5 & 4 & 10 & 8 \\
\hline SEP & 25 & 20 & 12,500 & 20,000 & 5 & 4 & 5 & 4 \\
\hline OCT & 25 & 20 & 12,500 & 20,000 & 5 & 4 & 0 & 0 \\
\hline NOV & 25 & 20 & 12,500 & 20,000 & 5 & 4 & 20 & 16 \\
\hline DEC & 25 & 20 & 12,500 & 20,000 & 5 & 4 & 15 & 8 \\
\hline
\end{tabular}

Table 1: Short Term Model on Self-Help Financial System to Create Wealth for

Self-Employed (Sole Proprietors) In Ghana

Source: Field Study 2016

The following observations can be made from the model. Sole proprietorship by definition is a business set up which needs limited capital to establish and for that matter it is the easiest business organization that can be formed by individuals (Abor 2006). As the initial start-up capital could relatively be small expansion of the set up takes time and it is reported by many researchers that availability of funds is one of the teething problems facing sole proprietors in many economies and 
Ghana is no exception (Dzidonu 2003; Abor, 2006). Galbraith, (2015) suggested that it would be beneficial for two or more sole proprietors to contribute resources and assist each/ one another in their bid to create available funds for themselves. The model suggests that as small and medium scale enterprises have expressions in almost all trades (primary, secondary and tertiary) an agreed number of like-minded sole proprietors (small and medium scale enterprises) can have a pool of resources which they can lay hands on to assist members at an agreed time period.

For example, it is assumed in the model that there are two groups of sole proprietors (self-employed owners) who are like-minded and are prepared to contribute a certain sum of money every month for their own good without fail for a certain period of time. That is to say such like-minded prospective sole proprietors (self-employed owners) are dedicated and truthful individuals who are prepared to go by the tenets of agreement they have set for themselves without fail. Let us call the first group of people G1 who have agreed to contribute five hundred Ghana cedis (Ghc500.00) only each month for a year and the second group of people G2 who have also agreed to contribute one thousand Ghana cedis (Ghc1,000.00) only every month for a year. It is further assumed that twenty five (25) people paid the Ghc500.00 and twenty (20) people paid the Ghc1, 000.00 .

At the end of the first month (say January) an amount of twelve thousand, five hundred Ghana cedis (Ghc12, 500.00) could be accumulated by the first group (G1) and an amount of twenty thousand Ghana cedis (Ghc20, 000.00) could be realized by the second group (G2). These accumulated funds could be put to good use if the members in each group decide to disburse the said sums of money in a certain agreed formula say five members in group one (G1) will benefit from the proceeds each month and four members could benefit from the generated income in group two (G2) each month. If the formula in terms of numbers is agreed then each of the five first beneficiary members in group one (G1) will get two thousand five hundred Ghana cedis (Ghc2, 500.00) in the first month while each member in group (G2) in the first month could get a substantial amount of money - five thousand Ghana cedis (Ghc5, 000.00) within the first month. The method could be repeated for five conservative times (in terms of months) and at the end of the fifth time each member in group one (G1) would have been given two thousand five hundred Ghana cedis (Ghc2, 500.00) an amount which most of them would not have got if not for their mutual agreement and commitment. Conversely, in group two by the end of the fourth month each member would have received five thousand Ghana cedis (Ghc5, 000.00).

From the arrangements it could be deduced that by the end of the twelve months in a year each member in group one (G1) could lay hands on an amount of five thousand Ghana cedis (Ghc5, 000.00) within ten months of the twelve months of the year without paying any interest which would have been a requirement if such money had been contracted from a bank or a financial institution which would have called for payment of interest in addition to the principal amount received. Members in group two (G2) stand to benefit greatly as regards their relatively higher contributions. Each member in the group would have grasped ten thousand Ghana cedis (Ghc10, 000.00) within ten months without paying any interest to any financial institution that might have granted the loan within ten months. The implication is that if the members in the groups commit themselves to the tenets and continue with their mutual contributions for say four conservative years then large sums of monies could accrue to them in their bid to do business. For example, each member in group 1 at the end of four years could grasp twenty thousand Ghana cedis (Ghc20, 000.00) and those in group 2 could receive forty thousand cedis (Ghc 40,000) at the end of four years. It is the hope of the researchers that the idea would be accepted by sole proprietors who are struggling to generate the needed funds for their businesses because the model seeks to encourage prospective businessmen/ women to develop selfhelp savings that aims at eradicating the incidence of payment of principal amount paid in addition to high interest rates and in some cases unscrupulous financial institutions running away with the hard worn monies kept with them (financial institutions) by businessmen and women.

It should be noted that model 1 would be able to be effective if the following conditions are met.

- First, there should be people who are like-minded

- Second, such like-minded people are truthful to the group

- Third, that the contributors are willing and able to honour their financial obligations to the group when the time is due without fail

- $\quad$ Fourth, each member cannot withdraw the membership status until the agreed time period (at least one year) expires.

- No member/ contributor will be allowed to withdraw part of the monies deposited or even the whole amount of money contributed in times of need.

- That the contributors will live for the period set for them if all other things are equal.

- As death and other human actions like migration and sickness are likely to happen to human beings in one's life time during a certain time period the like- minded contributors can agree to insure some of the lump sum of money generated from their contributions each month with an insurance company so that in the event of any mishap the group can rely on their insurance policy to cater for that.

Model 2 is also a self-help model that seeks to create wealth for sole proprietors (self-employed owners) in the long run in Ghana. It would be appropriate for small and medium scale enterprises or sole proprietors who might have started their businesses though it could be beneficial to small scale businessmen/women who want to set up their own businesses. The aim of the model is to assist owners of self-employed businesses especially sole proprietors and would-be sole proprietors to raise their own funds in the long run period without resorting to the banking institutions that normally charge higher 
interest rates and also in some case run away with their hard earned incomes thereby making them poorer than they were before.

\begin{tabular}{|c|c|c|c|c|c|c|}
\hline \multicolumn{7}{|c|}{ Number of Years } \\
\hline $\begin{array}{c}\text { Denomination } \\
\text { Gh\& }\end{array}$ & Week Ghф & Month Ghф & $1 \mathrm{Gh \phi}$ & $5 \mathrm{Gh} \phi$ & $10 \mathrm{Gh} \phi$ & $20 \mathrm{Gh} \phi$ \\
\hline 1 & 5 & 20 & 240 & 1200 & 12000 & 240000 \\
\hline 2 & 10 & 40 & 480 & 2400 & 24000 & 480000 \\
\hline 5 & 25 & 100 & 1200 & 6000 & 60000 & 1200000 \\
\hline 10 & 50 & 200 & 2400 & 12000 & 12000 & 2400000 \\
\hline 20 & 100 & 400 & 4800 & 24000 & 240000 & 4800000 \\
\hline 50 & 250 & 1000 & 1200 & 60000 & 600000 & 12000000 \\
\hline
\end{tabular}

Table 2: Self-Help Model to Create Wealth for Sole Proprietors in Ghana. (Long Term Model)

Source: Field Work 2016

The long term self-help model would be possible if the following assumptions are adhered to. First, the individual will choose a given denomination which he/ she is prepared to contribute daily without fail.

Second, the individual will select a long term period which will be convenient to him/ her. It is to be noticed that what is a long term period to one individual may be a short term period to the other person so the term long term period could be relative to business entities Neubaurer et al (2016).

Third, the individual should be prepared to make the daily contribution excluding Saturdays and Sunday for the said number of years set for the self. Saturdays are exempted because the researchers are of the view that people including the one making the contribution attend funerals and as it is a social responsibility of people in most Ghanaian societies that daily contribution on that day may inconvenience the contributor. Sundays are also exempted because many people go to church that day and their various church activities could serve as impediments to the contributions. It should also not be forgotten that some people go to church or to the mosque on Saturdays and Fridays respectively. Such people can substitute any of the days identified (Saturday or Sunday) for their periodic contributions instead of the day for their worship. It must be stated that the individual can make the contributions all the days of the week if the one wishes and in this case the one stands to benefit a lot from the model. set for the self.,

Fourth, that the one making the contributions will not make any withdrawals in any form during the long term period beyond.

Fifth, it is assumed that the individual making the contributions will live for the years set for the long term and

Sixth, it is also assumed that inflationary rates and depreciation in the value of the money saved remain constant.

Seventh, in order that the individual will not be tempted to withdraw money from the periodic contributions and for $\mathrm{him} /$ her to generate additional income for him/ herself in the long run period, the individual is advised to make the various contributions into a savings bank. The money saved with a savings bank will generate some additional income in the form of interest for the accounts holder.

From table 2 it is seen that if an individual decides to contribute one Ghana cedi (Ghs1.00) a day excluding Saturdays and Sundays that individual within a week could have saved five (Ghs5.00) Ghana cedis. He/ she would have saved two hundred and forty cedis (Ghs240.00) within a year and if the long run period for that person is say ten years then an amount of twelve thousand Ghana cedis (Ghs12, 000.00) could be saved by that person if he/ she abides by the tenets of the model. A hooping sum of money, sixty thousand Ghana cedis (Ghs60,000.00) would be accrued by the individual if he contributes five Ghana cedis (Ghs5.00) daily for five days a week and continuously does that for ten years.

\section{Conclusion}

The researchers are of the opinion that some banks and other financial institutions in Ghana have been a liability rather than assets to some well-meaning Ghanaians in their bid in doing business with them. This is so because banks normally charge interests on the principal amount given to clients so a customer who collects a loan from a bank repays the original amount in addition to the principal amount collected. Also it is on record that some unscrupulous financial institutions run away with monies deposited with them by customers. A case in point is DKM and other financial institutions that have defrauded their customers in the Brong-Ahafo region in Ghana. These models have been designed to serve as guides to prospective businessmen/ women who would want to provide their own sources of income for their businesses without relying on the banks and other financial institutions. 


\section{References}

i. Amankwah, J. Y. (2006). Assessing the effects of Recent Labour Market Interaction on Poverty in Ghana. In Labour Growth: Better Jobs. Carleton University Press Ottawa, Canada

ii. Baah, Y. A. (2007). Organizing the informal Economy. Experience and lessons from Asia and Africa; Ghana TUC, LOFTF (Denmark) Project, TUC. Accra.

iii. Cook, S. \& Bbinford, L. (2012). Obliging need: Rural Petty industry in Mexican Capitation. University of Texas Press.

iv. Farrell, G., Roman, J. \& MMattlow, F. (2000). Conceptualizing Shadow Economy. Journal of International Affairs. Vol53. (2) 393

v. Galbraith, J. K. (2015). The new industrial state. Princeton University Press.

vi. Ghana Statistical Service, (2008/ 10).Population and Housing Census: Providionsl Results; Accra.

vii. Miller, D (2008). National responsibility and global justice. Critical review of International Social and Political Philosophy. 11 (4) 383-399.

viii. Nelson, J. M. (2017). Access to Power: Politics and the Urban Poor in developing Nations. Princeton University Press.

ix. Neubauer, F. \& Lank, A. G. (2016). The family business. Tts governance for Sustainability. Springer.

x. Nsowah-Nuamah, N. N. N. \& Amankwah, J. Y. (2003). Report on Registration of Unemployed and underemployed persons: Ministry of Manpower Development and Employment. Accra. Ghana.

xi. Nugent, N. (2017). The government and politics of the European Union. Springer.

xii. Nyameky, M., Kabore, N., Bonego,E. R., Kiema, E, Ndour, B., Jalla, S. A. \&Tarawally, M. S. (2009). Organizing Informal Sector Workers in West Africa Women workers; Trade Union Strategies: Case Study; Ghana. Accra; Ghana TUC.

xiii. Osarekhoe, A. (200). Oxymoron of informal Economy. A framework for Conceptualizing informal sector as enabler of economic development in Developing countries. Journal of International Business and Economics Issue 1 vol: 9.

xiv. Osei-Boaten, C. \& Ampratwum, E. (2011). The informal sector in Ghana. Accra; Friedrich Ebert Stiftung.

xv. Owusu-Ansah, D. (2014). Historical dictionary of Ghana. Rowman \& Littlefield.

xvi. Warr, P. \& Inceogln, I. (2017). Work orientations, well-being and job content of Self-employed and employed professionals. Work employment \& society.095001707717684.

xvii. Wolf, E. R. (2010). Europe and the people without history. University of California Press. 